Provided for non-commercial research and education use. Not for reproduction, distribution or commercial use.

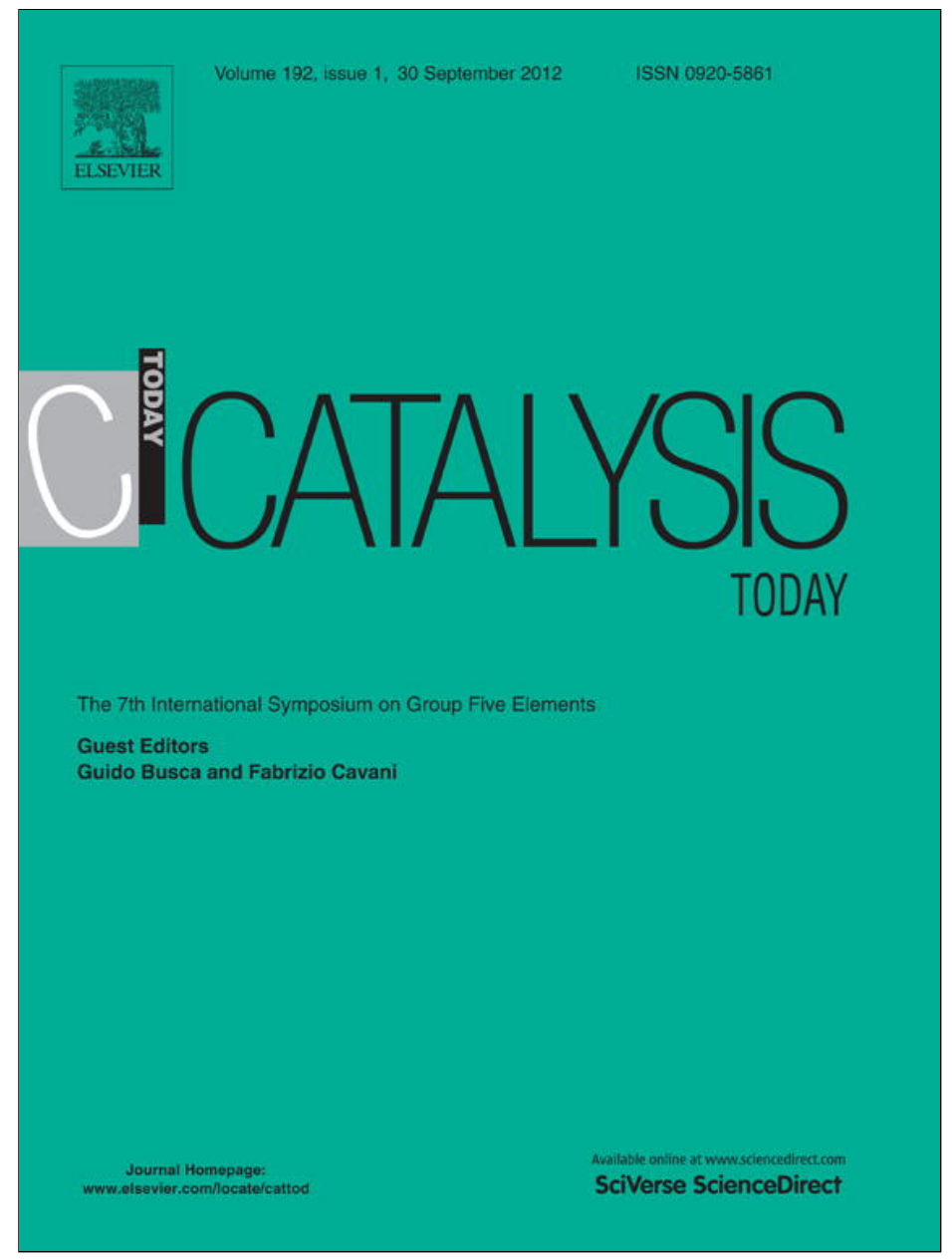

This article appeared in a journal published by Elsevier. The attached copy is furnished to the author for internal non-commercial research and education use, including for instruction at the authors institution and sharing with colleagues.

Other uses, including reproduction and distribution, or selling or licensing copies, or posting to personal, institutional or third party websites are prohibited.

In most cases authors are permitted to post their version of the article (e.g. in Word or Tex form) to their personal website or institutional repository. Authors requiring further information regarding Elsevier's archiving and manuscript policies are encouraged to visit:

http://www.elsevier.com/copyright 


\title{
Salophen and salen oxo vanadium complexes as catalysts of sulfides oxidation with $\mathrm{H}_{2} \mathrm{O}_{2}$ : Mechanistic insights
}

\author{
A. Coletti ${ }^{\mathrm{a}}$, P. Galloni ${ }^{\mathrm{a}}$, A. Sartorel ${ }^{\mathrm{b}}$, V. Conte $^{\mathrm{a}, *}$, B. Floris $^{\mathrm{a}}$ \\ a Dipartimento di Scienze e Tecnologie Chimiche, Università di Roma Tor Vergata, via della Ricerca Scientifica snc, 00133 Roma, Italy \\ ${ }^{\mathrm{b}}$ Dipartimento di Scienze Chimiche, Università di Padova, via Marzolo 1, 35131 Padova, Italy
}

\section{A R T I C L E I N F O}

\section{Article history:}

Received 8 November 2011

Received in revised form 5 March 2012

Accepted 8 March 2012

Available online 26 April 2012

\section{Keywords:}

Catalytc oxidation

Vanadium complexes

Substituent effect

${ }^{51} \mathrm{~V}$ NMR

DFT calculation

\begin{abstract}
A B S T R A C T
The application of $\mathrm{V}(\mathrm{V})$ catalysts in oxidation of sulfides with peroxides offers an efficient procedure, that is compatible with different functional groups, and leads to good yields and selectivities. However, the understanding of the factors affecting the reactivity of different catalysts is still far to be complete. An experimental and theoretical study on a series of $\mathrm{V}(\mathrm{V})$ complexes containing variously substituted salen and salophen ligands is reported with the aim to correlate the activity of the catalysts with the electronic character of the vanadium center. The results obtained indicate that steric factors play a major role in determining the outcome of the reaction, often overcoming the electronic effects. Theoretical results suggest the intervention in the catalytic cycle of an hydroperoxo vanadium species.
\end{abstract}

(C) 2012 Elsevier B.V. All rights reserved.

\section{Introduction}

Oxidation reactions, and in particular their catalytic versions, often represent key processes to transform bulk chemicals into valuable materials. Millions of tons of such compounds are yearly produced worldwide, and find applications in all areas of chemical industries [1].

On the basis of economic and environmental reasons [2,3], oxidation processes with $\mathrm{H}_{2} \mathrm{O}_{2}$ are sustainable processes: first of all $\mathrm{H}_{2} \mathrm{O}_{2}$ is, besides dioxygen, the most appealing oxidant and the one with the highest "atom efficiency" (47\% of active oxygen); in addition, aqueous hydrogen peroxide is readily accessible, safe to use and upon reduction only water is formed [4-7]. Catalytic systems based on different metals have been employed in conjunction with hydrogen peroxide for oxidation reactions [5]. Vanadium catalyzed oxidations with hydrogen peroxide have attracted interest of several research groups because of the interesting properties of this metal in terms of selectivity, reactivity and stereoselectivity. In this perspective, these reactions are also interesting because of the relationship with the reactivity of vanadium-dependent haloperoxidases (VHPO) enzymes, species able to activate hydrogen peroxide for the oxidation of halides, thus producing halogenated compounds, and for stereoselective sulfoxidations of appropriate substrates [8-10].

\footnotetext{
* Corresponding author. Tel.: +39 0672594014; fax: +39 0672594328

E-mail address: valeria.conte@uniroma2.it (V. Conte).
}

Peroxovanadium complexes, formed upon interaction of the metal ion with $\mathrm{H}_{2} \mathrm{O}_{2}$, depending on the nature of the ligands coordinated to the metal and on the experimental conditions, can act either as electrophilic oxygen transfer reagents or as radical oxidants [11]. Typical electrophilic processes are the oxidation of sulfides and tertiary amines and the epoxidation of allylic alcohol or simple alkenes [11-13]. The oxidation of alcohols and the hydroxylation of aliphatic and aromatic hydrocarbons are examples of homolytic reactivity $[5,12,14]$. Several review articles have appeared recently on vanadium-catalyzed oxidations $[5,15,16]$.

Additionally, the oxidation of sulfur containing compounds remains an hot research topic both from a synthetic point of view [11,17-19] i.e. the preparation of chiral sulfoxides and of sulfones, as well as considering modern processes for desulfurization of fuels [20]. The removal of sulfur from diesel oil and gasoline is becoming more and more important, not only to protect car exhaust catalysts, but also because of the more strict environment-protecting regulations. Up-to-date, hydrodesulfurization is the method of choice to remove thiols, sulfides, and disulfides, but with this process it is not possible to efficiently remove aromatic sulfur-containing compounds, such as dibenzothiophene and 4,6-dimethyldibenzothiophene. To achieve ultra-deep desulfurization of fuels, oxidation reaction appears to be a promising procedure [21].

This background prompted us to explore the catalytic activity of selected vanadium complexes in oxidation reactions starting from a model sulfide, $\mathrm{Ph}-\mathrm{S}-\mathrm{CH}_{3}$, selectively to the corresponding 


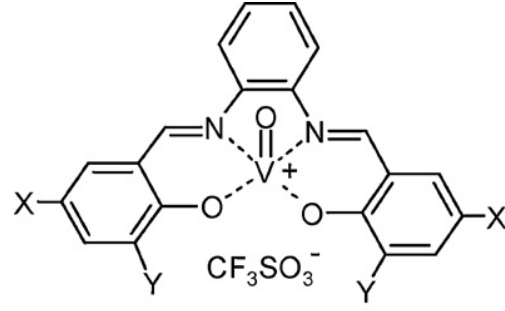

$$
\begin{aligned}
& X=Y=C l \\
& X=C l \quad Y=H \\
& X=Y=H \\
& X=t-B u \quad Y=H \\
& X=Y=t-B u \\
& X=H \quad Y=t B u \\
& X=O M e \quad Y=H
\end{aligned}
$$

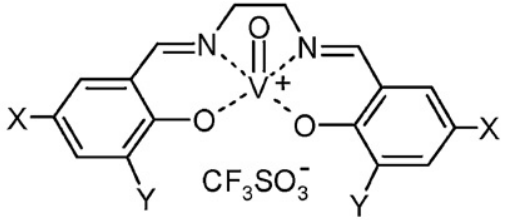

$$
\begin{aligned}
& X=Y=C l \\
& X=C l \quad Y=H \\
& X=Y=H \\
& X=t-B u \quad Y=H \\
& X=Y=t-B u \\
& X=H \quad Y=O M e \\
& X=O M e \quad Y=H
\end{aligned}
$$

Scheme 1. Vanadium(V) salen and salophen complexes.

sulfoxide. The structure of the catalysts used in this study is reported in Scheme 1, they are all oxo vanadium(V) species, ligated with Schiff bases derived from the appropriate substituted salicylaldehydes and $o$-phenylendiamine or 1,2-ethanediamine respectively.

Salophen and salen derivatives are considered "privileged ligands" because their easy synthesis by condensation between aldehydes and amines, they also coordinates a wide variety of metals [22]. In addition, stereogenic centers or other elements of chirality can be also introduced. Moreover after appropriate modification heterogeneous catalysts [23] can be prepared.

The variation of the coordination sphere was designed in order to highlight correlation between the electronic distribution on the metal center with the reactivity in oxidation reactions, similar approach has been recently used with vanadium containing strongly related salen and salan complexes [24].

The catalytic activity of some of the species here studied was already recently analyzed in our labs, in the epoxidation of cyclooctene [25]. Quite surprisingly, electron withdrawing groups in the periphery of the salophen ligands reduced the catalytic activity of the vanadium complex toward double bonds. However, this aspect was attributed to faster decomposition of the peroxide. On the other hand, with oxo vanadium salophen complex possessing four $t$-butyl groups in the backbone, the observed reactivity toward cyclooctene was almost zero. In this latter case the prevalence of the steric effect over the electronic one is evident, i.e. the bulkiness of the ligand heavily hamper the approach of the substrate to the peroxo complex. Accordingly, in that work [25] no clear cut correlation between the observed reactivity and the coordination environment of the metal center was envisaged.

Moreover, it is to be kept in mind that in vanadium catalyzed oxidations with $\mathrm{H}_{2} \mathrm{O}_{2}$ two competitive reactions occur: the oxidation of the substrate and the vanadium catalyzed decomposition of hydrogen peroxide [26], for that reason a higher activity of a vanadium complex may simply result in a faster decomposition of $\mathrm{H}_{2} \mathrm{O}_{2}$.

In this paper we present an experimental and theoretical study, concerning the effects of steric and electronic modification of the ligands on the catalytic activity of salophen and salen oxo vana$\operatorname{dium}(\mathrm{V})$ complexes in the oxidation of $\mathrm{PhSMe}$ with $\mathrm{H}_{2} \mathrm{O}_{2}$. This easy to oxidize model substrate has been chosen with the aim to obtain fast and clean oxidation process, good prerequisite for analyzing a class of catalysts which have already shown ambiguous kinetic behavior as function of the substituents present in the salophen or salen scaffolds [25].

\section{Procedures}

\subsection{Experimental}

Caution: The uncontrolled heating of large amounts of peroxides must be avoided. Care should be exercised in order to avoid possible explosion.

\subsubsection{Instruments}

${ }^{1} \mathrm{H}$ NMR spectra were recorded on a Bruker Avance $300 \mathrm{MHz}$ spectrometer, with $\mathrm{CDCl}_{3}, \mathrm{CD}_{3} \mathrm{CN}$ or $\mathrm{CD}_{3} \mathrm{COCD}_{3}$ as solvents. ${ }^{11} \mathrm{~V}$ NMR spectra were recorded on a Bruker Avance $400 \mathrm{MHz}$ spectrometer, in $\mathrm{CD}_{3} \mathrm{CN}$. HPLC analyses were carried out with a Shimadzu LC-10 ADvp instrument with UV-vis SPDM10Avp detector and a Kromasil $100 \mathrm{C} 18(250 \mathrm{~mm} \times 4.6 \mathrm{~mm}, 5 \mu \mathrm{m})$ column with $\mathrm{V}^{\mathrm{V}}$ complexes or a Metachem Metaphor 50 ODS-2 $(250 \mathrm{~mm} \times 4.6 \mathrm{~mm}$, $5 \mu \mathrm{m}$ ) for oxidation reactions. UV-visible spectra were recorded on a SHIMADZU 2450 spectrometer equipped with the UV Probe 2.34 program.

\subsubsection{Materials}

HPLC-purity grade MeCN was used. Methanol and dichloromethane commercial grade purity were purchased and used as such. Spectroscopic-grade solvents were used for UV-vis spectra. Commercially available aqueous solution of $\mathrm{H}_{2} \mathrm{O}_{2}$ were used after iodometric titration $\left(10.4 \pm 0.2 \mathrm{M} \mathrm{H}_{2} \mathrm{O}_{2}\right.$ in water).

\subsubsection{Synthesis of ligands}

The Schiff bases used for the synthesis of the catalysts were prepared by the well known reaction between salicylaldehyde and diamine. Slight experimental variations were introduced with respect to literature methods [27] and the resulting procedure was successfully applied to a number of differently substituted aldehydes.

General procedure: Two equivalents of the appropriate salicylaldehyde were dissolved in the minimum volume of boiling methanol (generally, $20 \mathrm{ml}$ ) and added dropwise with one equivalent of diamine (either 1,2-diaminoethane or 1,2-benzenediamine) in $5 \mathrm{ml}$ methanol. The solution was refluxed until all the aldehyde disappeared (TLC analysis) and then cooled to room temperature, thus causing precipitation of the Schiff base, as a yellow solid. The filtered solid was washed with a small amount of methanol, then with diethyl ether and dried. The following Schiff bases were prepared: 
Salophen, [1,2-bis-(salicylideneamino)benzene]: yield 95.3\%; 5,5'- $\mathrm{Cl}_{2}$ salophen, [1,2-bis-(5-Cl-salicylideneamino)benzene]: yield >99\%; $5,5^{\prime}-(t-B u)_{2}$ salophen [1,2-bis-(5-t-Bu-salicylideneamino)benzene]: yield 75\%; 3,3'-(OMe $)_{2}$ salophen, [1,2-bis-(3OMe-salicylideneamino)-benzene]: yield $77 \%$; $5,5^{\prime}-(\mathrm{OMe})_{2}$ salophen, [1,2-bis-(5-OMe-salicylideneamino)-benzene]: yield 79\%; 3,3',5,5'- $\mathrm{Cl}_{4}$ salophen [1,2-bis-(3,5- $\mathrm{Cl}_{2}$ salicylideneamino)benzene]: yield $95 \% ; 3,3^{\prime}, 5,5^{\prime}-(t-B u)_{4}$ salophen [1,2-bis-(3,5-di- $t$ Bu-salicylideneamino)benzene]: yield $75 \%$.

Salen, [1,2-bis-(salicylideneamino)ethane]: yield 88\%; 5,5'$\mathrm{Cl}_{2}$ salen, [1,2-bis-(5-Cl-salicylideneamino)ethane]: yield 67\%; $5,5^{\prime}-(t-B u)_{2}$ salen, $\quad[1,2$-bis-(5-t-Bu-salicylideneamino $)$ ethane]: yield 91\%; 3,3'-(OMe) $)_{2}$ salen, [1,2-bis-(3-methoxy-salicylideneamino)ethane]: yield $92 \% ; 5,5^{\prime}-(\mathrm{OMe})_{2}$ salen, [1,2-bis(5-OMe-salicylideneamino)ethane]: yield $92 \% ; 3,3^{\prime}, 5,5^{\prime}-\mathrm{Cl}_{4}$ salen, [1,2-bis-(3,5- $\mathrm{Cl}_{2}$-salicylideneamino)ethane]: yield 70\%; 3,3',5,5'$(t \text {-Bu })_{4}$ salen, $\quad\left[1,2\right.$-bis- $\left(3,5-(t-B u)_{2}\right.$-salicylideneamino $)$ ethane]: yield $72 \%$.

All the compounds gave ${ }^{1} \mathrm{H}$ NMR and UV-vis spectra consistent with the structure and with literature data $[25,28-30]$.

\subsubsection{Synthesis of $V^{I V}$ complexes}

The synthesis of these complexes was accomplished by a procedure slightly different form that reported in the literature $[31,32]$. A number of the vanadium derivatives used in the literature were tested as precursors, i.e. $\mathrm{VO}$ (acetylacetonate) ${ }_{2}$ [31], vanadyl sulfate di-hydrate [29,33], and V(acetylacetonate $)_{3}$ [34]. The best results were obtained with $\mathrm{V}^{\mathrm{III}}(\mathrm{acac})_{3}$, in terms of reproducibility of the reaction and solubility of complexes.

General procedure: The Schiff base was dissolved in $100 \mathrm{ml}$ of boiling methanol, or suspended when scarcely soluble. The equimolar amount of $\mathrm{V}(\mathrm{acac})_{3}$ was completely dissolved in the minimum volume of $\mathrm{MeOH}$ with the help of sonication and added dropwise to the solution (or to the suspension), causing immediate color change from yellow to green. After an overnight stirring in an open vessel at room temperature, the reaction was stopped and the precipitated solid was collected, washed with diethyl ether, and dried. No trace of Schiff base was present. Eventually unreacted $\mathrm{V}(\mathrm{acac})_{3}$ was washed off with warm acetone.

The following $\mathrm{V}^{\mathrm{IV}} \mathrm{O}$ complexes were prepared, their purity was checked with TLC and HPLC analyses.

SalophenV $\mathrm{IV}_{\mathrm{O}}$, yield $73 \%$, UV-vis in $\mathrm{MeCN}\left[\lambda_{\max }, \mathrm{nm}(\varepsilon\right.$, $\left.\left.\mathrm{M}^{-1} \mathrm{~cm}^{-1}\right)\right] 242$ (40,000), 314 (22,000) and 396 (18,000); 5,5'$\mathrm{Cl}_{2}$ salophenV $\mathrm{IV}^{\mathrm{IV}}$, yield $78 \%$, UV-vis in $\mathrm{MeCN}\left[\lambda_{\max }, \mathrm{nm}(\varepsilon\right.$,

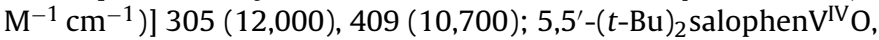
yield $82 \%$, UV-vis in MeCN $\left[\lambda_{\max }, \mathrm{nm}\left(\varepsilon, \mathrm{M}^{-1} \mathrm{~cm}^{-1}\right)\right] 246(40,900)$, 318 (22,700), $409(15,400) ; 3,3^{\prime}-(\mathrm{OMe})_{2}$ salophen $\mathrm{V}^{\mathrm{IV}} \mathrm{O}$, yield $79 \%$, UV-vis in MeCN $\left[\lambda_{\max }, \mathrm{nm}\left(\varepsilon, \mathrm{M}^{-1} \mathrm{~cm}^{-1}\right)\right] 221(42,000), 301$ $(24,000), 313(22,000)$ and $335(13,000) ; 5,5^{\prime}-(\mathrm{OMe})_{2}$ salophenV $^{\mathrm{IV}} \mathrm{O}$, yield $87 \%$, UV-vis in $\mathrm{MeCN}\left[\lambda_{\max }, \mathrm{nm}\left(\varepsilon, \mathrm{M}^{-1} \mathrm{~cm}^{-1}\right)\right] 216(70,000)$, 243 (41,000), 289 (30,000), 300 (32,000), $337(26,000)$ and 434 (9000); 3,3',5,5'-Cl ${ }_{4}$ SalophenV $V^{\mathrm{IV}} \mathrm{O}$ : yield $78 \%$, UV-vis in $\mathrm{MeCN}$ $\left[\lambda_{\max }, \mathrm{nm}\left(\varepsilon, \mathrm{M}^{-1} \mathrm{~cm}^{-1}\right)\right] 315$ (9800), $412(10,000) ; 3,3^{\prime}, 5,5^{\prime}-$ $(t \text {-Bu })_{4}$ salophenV $\mathrm{IV}^{\mathrm{IV}} \mathrm{O}$, yield $87 \%, \mathrm{UV}$-vis in $\mathrm{MeCN}\left[\lambda_{\max }, \mathrm{nm}(\varepsilon\right.$, $\left.\left.\mathrm{M}^{-1} \mathrm{~cm}^{-1}\right)\right] 250$ (43,300), 327 (25,900), $416(16,100)$.

SalenV $\mathrm{V}^{\mathrm{IV}} \mathrm{O}$, yield $89 \%$, UV-vis in $\mathrm{MeCN}\left[\lambda_{\max }, \mathrm{nm}\left(\varepsilon, \mathrm{M}^{-1} \mathrm{~cm}^{-1}\right)\right]$ 242 (39,000), $277(18,000)$ and 362 (7900); 5,5'-Cl salenV $^{\mathrm{IV}} \mathrm{O}$, yield $67 \% \mathrm{UV}$-vis in MeCN $\left[\lambda_{\max }, \mathrm{nm}\right] 248(49,000), 280 \mathrm{sh}$, 370 (7400); 5,5'-(t-Bu $)_{2}$ salenV $\mathrm{V}^{\mathrm{IV}} \mathrm{O}$, yield $67 \%$, UV-vis in $\mathrm{MeCN}$ $\left[\lambda_{\max }, \mathrm{nm}\left(\varepsilon, \mathrm{M}^{-1} \mathrm{~cm}^{-1}\right)\right] 246(56,000), 278(27,000), 370$ (9200); $3,3^{\prime}-(\mathrm{OMe})_{2}$ salenV $\mathrm{IV}_{\mathrm{O}}$, yield $93 \%$, UV-vis in MeCN $\left[\lambda_{\max }, \mathrm{nm}(\varepsilon\right.$, $\left.\left.\mathrm{M}^{-1} \mathrm{~cm}^{-1}\right)\right] 224$ (16,000), $296(14,000)$ and 381 (2800); 5,5'$(\mathrm{OMe})_{2}$ salenV $^{\mathrm{IV}} \mathrm{O}$, yield $86 \%$, UV-vis in $\mathrm{MeCN}\left[\lambda_{\max }, \mathrm{nm}(\varepsilon\right.$, $\left.\left.\mathrm{M}^{-1} \mathrm{~cm}^{-1}\right)\right] 251$ (20,000), $286 \mathrm{sh}$ (8800) and 392 (9000); 3,3',5,5'$\mathrm{Cl}_{4}$ salenV ${ }^{\mathrm{IV}} \mathrm{O}$, yield $70 \%$, UV-vis in MeCN: $\lambda_{\max }=370 \mathrm{~nm}$ (does not dissolve completely); $3,3^{\prime}, 5,5^{\prime}-(t-B u)_{4} \operatorname{salenV}^{\mathrm{IV}} \mathrm{O}$, yield $72 \%$, UV-vis in $\mathrm{CH}_{2} \mathrm{Cl}_{2}\left[\lambda_{\max }, \mathrm{nm}\left(\varepsilon, \mathrm{M}^{-1} \mathrm{~cm}^{-1}\right)\right] 252(41,000), 288(27,000)$ and 386 (3600). UV-vis spectra are consistent with literature data $[35,36]$.

\subsubsection{Synthesis of $V^{V}$ complexes}

The synthesis of these complexes was accomplished by a procedure slightly different form that reported in the literature [34]. For all compounds ${ }^{1} \mathrm{H}$ NMR spectra are in agreement with the structure (in $\mathrm{CD}_{3} \mathrm{CN}$, aromatic protons resonate in the range 7.1-7.8 ppm, $\mathrm{CH}=\mathrm{N}$ protons in the range $8.2-8.9 \mathrm{ppm}$, and $-\mathrm{CH}_{2}-$ protons of salen complexes are around $4.4 \mathrm{ppm}$ ). By comparison with authentic samples, TLC and HPLC analyses excluded the presence of $\mathrm{V}^{\mathrm{IV}}$ species.

General procedure: $200 \mathrm{mg}$ of $\mathrm{V}^{\mathrm{IV}} \mathrm{O}$ complex were dissolved in $30 \mathrm{ml} \mathrm{CH}_{2} \mathrm{Cl}_{2}$ under stirring. Dioxygen was bubbled $5 \mathrm{~min}$ into the solution kept at $0^{\circ} \mathrm{C}$ and $\mathrm{O}_{2}$ atmosphere was ensured with a latex reservoir. 1.2 Equivalents trifluoromethanesulfonic acid were rapidly added, causing darkening of the solution and precipitation of a solid. The reaction mixture was allowed to reach room temperature and stirred until disappearance of $\mathrm{V}^{\mathrm{IV}}$ species $(5 \div 20 \mathrm{~h})$. Fine powder of $\mathrm{V}^{\mathrm{V}}$ complex was isolated after centrifugation of the reaction mixture (6000 r.p.m.) and decantation of the supernatant solution.

The following $\mathrm{V}^{\mathrm{V}} \mathrm{O}$ complexes were prepared.

[salophenV $\mathrm{V}^{\mathrm{O}}$ ] $\mathrm{CF}_{3} \mathrm{SO}_{3}$, yield 95\% $\mathrm{UV}$-vis in $\mathrm{MeCN}\left[\lambda_{\max }, \mathrm{nm}\right.$ $\left.\left(\varepsilon, \mathrm{M}^{-1} \mathrm{~cm}^{-1}\right)\right] 242$ (40,000), $304(26,000)$ and 393 (10,000); [5,5'$\mathrm{Cl}_{2}$ salophenV $\left.{ }^{\mathrm{V}} \mathrm{O}\right] \mathrm{CF}_{3} \mathrm{SO}_{3}$, yield $98 \%$, UV-vis in $\mathrm{MeCN}[\lambda$ max, $\mathrm{nm}(\varepsilon$, $\left.\left.\mathrm{M}^{-1} \mathrm{~cm}^{-1}\right)\right] 303(21,300), 408(11,200) ;\left[\right.$ [5, $5^{\prime}-(t-\mathrm{Bu})_{2}$ salophenV $\left.^{\mathrm{V}} \mathrm{O}\right]$ $\mathrm{CF}_{3} \mathrm{SO}_{3}$, yield $35 \%$, UV-vis in MeCN $\left[\lambda\right.$ max, $\left.\mathrm{nm}\left(\varepsilon, \mathrm{M}^{-1} \mathrm{~cm}^{-1}\right)\right] 245$ (42,700), 320 (24,300), 407 (14,400); [3,3'-(OMe $)_{2}$ salophenV $\left.^{\mathrm{V}} \mathrm{O}\right]$ $\mathrm{CF}_{3} \mathrm{SO}_{3}$, yield $75 \%$, UV-vis in $\mathrm{MeCN}\left[\lambda_{\max }, \mathrm{nm}\left(\varepsilon, \mathrm{M}^{-1} \mathrm{~cm}^{-1}\right)\right] 220$ $(64,000), 251$ (37,000), $302(45,000), 310(42,000), 340(24,000)$ and 437 (7200); [5,5'-(OMe $)_{2}$ salophenV $\left.{ }^{\mathrm{V}} \mathrm{O}\right] \mathrm{CF}_{3} \mathrm{SO}_{3}$, yield $82 \%$, UV-vis in $\operatorname{MeCN}\left[\lambda_{\max }, \mathrm{nm}\left(\varepsilon, \mathrm{M}^{-1} \mathrm{~cm}^{-1}\right)\right] 215(68,000), 242(41,000)$, 292 (46000), 300 (45000), 341 (29000) and 435 (4900); [3,3',5,5'$\mathrm{Cl}_{4}$ SalophenV $\left.\mathrm{V}^{\mathrm{O}}\right] \mathrm{CF}_{3} \mathrm{SO}_{3}$, yield $35 \%,\left[\lambda_{\max }, \mathrm{nm}\left(\varepsilon, \mathrm{M}^{-1} \mathrm{~cm}^{-1}\right)\right] 313$ (19200), $410(13,700) ;\left[3,3^{\prime}, 5,5^{\prime}-(t-B u)_{4}\right.$ salophenV ${ }^{\mathrm{V}} \mathrm{O}^{-1} \mathrm{CF}_{3} \mathrm{SO}_{3}$, yield $87 \%,\left[\lambda_{\max }, \mathrm{nm}\left(\varepsilon, \mathrm{M}^{-1} \mathrm{~cm}^{-1}\right)\right] 244(30,700), 326(35,300), 416 \mathrm{sh}$ (9300).

[salenV $\left.{ }^{\mathrm{O}} \mathrm{O}\right] \mathrm{CF}_{3} \mathrm{SO}_{3}$, yield $89 \%$, UV-vis in $\mathrm{MeCN}[\lambda \max , \mathrm{nm}(\varepsilon$, $\left.\left.\mathrm{M}^{-1} \mathrm{~cm}^{-1}\right)\right] 230$ (30,000), 296 (14,000) and 347 (7400); [5,5'$\mathrm{Cl}_{2}$ salenV $\mathrm{V}^{\mathrm{O}}$ ] $\mathrm{CF}_{3} \mathrm{SO}_{3}$, yield $67 \%$, UV-vis in $\mathrm{MeCN}[\lambda$ max, $\mathrm{nm}(\varepsilon$, $\left.\left.\mathrm{M}^{-1} \mathrm{~cm}^{-1}\right)\right] 230$ (30,000), 248 (24,000), and 285 (17,000); [5,5'$(t-\mathrm{Bu})_{2}$ salenV $\left.^{\mathrm{O}} \mathrm{O}\right] \mathrm{CF}_{3} \mathrm{SO}_{3}$, yield $5 \%$, UV-vis in $\mathrm{MeCN}\left[\lambda \lambda_{\max }, \mathrm{nm}\right.$ $\left.\left(\varepsilon, \mathrm{M}^{-1} \mathrm{~cm}^{-1}\right)\right] 230(33,400), 250(27,500) 290(19,000)$ and 348 (7500); [3,3'-(OMe $)_{2}$ salenV $\left.^{\mathrm{V}} \mathrm{O}\right] \mathrm{CF}_{3} \mathrm{SO}_{3}$, yield $58 \%$, UV-vis in $\operatorname{MeCN}\left[\lambda_{\max }, \mathrm{nm}\left(\varepsilon, \mathrm{M}^{-1} \mathrm{~cm}^{-1}\right)\right] 281(12,000), 308(10,000)$ and 359 (4200); [5,5'-(OMe $)_{2}$ salenV $\left.{ }^{\mathrm{V}} \mathrm{O}\right] \mathrm{CF}_{3} \mathrm{SO}_{3}$, yield $89 \%$, UV-vis in $\operatorname{MeCN}\left[\lambda_{\max }, \mathrm{nm}\left(\varepsilon, \mathrm{M}^{-1} \mathrm{~cm}^{-1}\right)\right] 288(12,000)$ and $391 \mathrm{sh}$ (3000); $\left[3,3^{\prime}, 5,5^{\prime}-\mathrm{Cl}_{4}\right.$ salenV $\left.\mathrm{V}^{\mathrm{O}}\right] \mathrm{CF}_{3} \mathrm{SO}_{3}$, yield $66 \%$, UV-vis in $\mathrm{MeCN}$ $\left[\lambda_{\max }, \mathrm{nm}\left(\varepsilon, \mathrm{M}^{-1} \mathrm{~cm}^{-1}\right)\right] 293 \mathrm{sh}(1300)$ and 345 sh (710); $3,3^{\prime}, 5,5^{\prime}-(t-B u)_{4}$ salenV $V^{V}$, yield $80 \%$. UV-vis in $\mathrm{CH}_{2} \mathrm{Cl}_{2}\left[\lambda_{\max }, \mathrm{nm}\right.$ $\left.\left(\varepsilon, \mathrm{M}^{-1} \mathrm{~cm}^{-1}\right)\right] 263$ (8000), 307 (5600) and $367 \mathrm{sh}(2900)$.

Cyclic voltammetry (CV) characterization reported elsewhere [37] confirmed the electronic effect of the substituents on the vanadium centers in these salen $\mathrm{V}^{\mathrm{IV}} \mathrm{O}$ and salophen $\mathrm{V}^{\mathrm{IV}} \mathrm{O}$ complexes. The higher redox potentials of the salophen complexes with respect to the salen ones indicate that the aromatic ring confers to vanadium a stronger Lewis acidity.

\subsubsection{Oxidation of phenyl methyl sulfide with $\mathrm{H}_{2} \mathrm{O}_{2}$, catalyzed by $V^{V}$ complexes}

The catalytic activity of all the complexes was tested in a probe reaction, i.e. oxidation of $\mathrm{PhSMe}$ with $\mathrm{H}_{2} \mathrm{O}_{2}$ in $\mathrm{MeCN}$. The reactions were performed with the same initial concentration of all the 
reactant species, at $25^{\circ} \mathrm{C}$ in a thermostated vessel. Product analysis was obtained by HPLC, to avoid thermal decomposition of products, adding a known amount of toluene as internal standard and using the response factors obtained by calibration straight lines. Stock solutions of sulfide and toluene in $\mathrm{MeCN}$ were used. The latter was periodically checked for the presence of oxidation product that were always absent. Solutions of $\mathrm{H}_{2} \mathrm{O}_{2}$ and the catalyst were prepared immediately before use.

$0.5 \mathrm{ml}$ of PhSMe $0.151 \mathrm{M}$ in $\mathrm{MeCN}$ and $0.15 \mathrm{ml}$ of catalyst $2.2 \times 10^{-3} \mathrm{M}$ in the same solvent were added to $5 \mathrm{ml} \mathrm{MeCN}$. $0.5 \mathrm{ml}$ of the resulting solution were taken and diluted to $5 \mathrm{ml}$ in a volumetric flask containing $2 \mathrm{ml}$ of PhMe $1.2 \times 10^{-3} \mathrm{M}$ in $\mathrm{MeCN}$, to measure initial sulfide concentration. The reaction started after addition of $0.18 \mathrm{ml}$ freshly prepared $\mathrm{H}_{2} \mathrm{O}_{2} 0.145 \mathrm{M}$ in $\mathrm{MeCN}$ (obtained diluting to $5 \mathrm{ml} 70 \mu \mathrm{l} 10.4 \pm 0.2 \mathrm{M} \mathrm{H}_{2} \mathrm{O}_{2}$ in water). Samples were taken at selected reaction times $(2,5,15$, and $40 \mathrm{~min})$ and analyzed at the HPLC.

\subsection{Calculations}

Pseudopotential LACVP was used for the energy optimization without symmetry constraints. Gaussian 03 program was used for geometry optimizations with the continuum solvent model [38]. Geometry optimizations were performed with Density Functional Theory (DFT) calculations using the B3LYP functional with the $6-31 G^{*}$ basis set $[39,40]$. Geometries were optimized at the B3LYP/LANL2DZ level, including solvent effects with the IEF-PCM method $(\mathrm{MeCN})$.

All the in vacuum quantum-mechanical calculations were carried out by using Spartan'08 [41].

\section{Results and discussion}

\subsection{Experimental}

\subsubsection{Reactivity}

The complexes prepared and used in this work contained Schiff base ligands possessing various substituents in the periphery of the aromatic scaffold, see Scheme 1.

All salophen and salen molecules have been prepared following literature procedures [27] starting from the appropriately substituted salicylaldehydes and $o$-phenylendiamine or 1,2-ethanediamine respectively. The various ligands have been subsequently used to synthesize all $\mathrm{V}^{\mathrm{IV}}$ and $\mathrm{V}^{\mathrm{V}}$ complexes in very good yields (see Section 2), following slightly modified literature procedures $[27,31,32,34]$ and the species obtained have been identified by comparison of their properties with literature data.

For comparison purposes, the $\mathrm{V}^{\mathrm{IV}}$ species, obtained in the first step of the synthesis of vanadates derivatives, were also tested as catalysts in the oxidation reactions, and the collected data were comparable to those observed (and discussed below) with $\mathrm{V}^{\mathrm{V}}$ complexes. However, the possible incursion of radical reactions, an expected event when $\mathrm{V}^{\mathrm{IV}}$ derivatives are used as catalysts in reactions with hydrogen peroxide [11], prompted us to examine the reactivity in oxidation reaction with hydrogen peroxide only with the catalysts in their highest oxidation state. In such a way, minimization of the vanadium catalyzed decomposition of $\mathrm{H}_{2} \mathrm{O}_{2}$ should occur.

The various substituents introduced in the scaffold of the complexes were chosen with the scope to modify the electronic character of the $\mathrm{V}^{\mathrm{V}}$ ion. Furthermore, a consistent comparison between the salophen and salen structure should help in divide the electronic from the structural effects, being the former species forced into a simil-planar configuration, while the latter can experience a fluctional behavior [22]. Accordingly, broader signals were detected in ${ }^{1} \mathrm{H}$ NMR spectra with salen complexes: i.e. signal for $\mathrm{CH}=\mathrm{N}$ at $9.23 \mathrm{ppm}$ shows a $\Delta v_{1 / 2}=7 \mathrm{~Hz}$ for $\left[3,3^{\prime}, 5,5^{\prime}-(t-\mathrm{Bu})_{4}\right.$ salophenV $\left.\mathrm{V}^{\mathrm{O}} \mathrm{O}\right] \mathrm{CF}_{3} \mathrm{SO}_{3}$ while for the corresponding $\left[3,3^{\prime}, 5,5^{\prime}-(t-\mathrm{Bu})_{4} \mathrm{salenV}^{\mathrm{V}} \mathrm{O}\right] \mathrm{CF}_{3} \mathrm{SO}_{3}$ derivative the same $\mathrm{CH}=\mathrm{N}$ signal at $8.86 \mathrm{ppm}$ shows a $\Delta \nu_{1 / 2}=22 \mathrm{~Hz}$.

The model reaction has been the oxidation with $\mathrm{H}_{2} \mathrm{O}_{2}$ of PhSMe to the corresponding sulfoxide, in $\mathrm{MeCN}$ at room temperature, the ratio $\mathrm{H}_{2} \mathrm{O}_{2}$ : Cat was ca. 50:1. A two-fold excess of the substrate with respect to the oxidant was used in order to ensure selectivity toward the sulfoxide and also to keep roughly constant the concentration of the substrate, at least at the beginning of the reaction.

The sulfide consumption and the sulfoxide formation were determined with quantitative HPLC analysis of the reaction mixture, see Section 2 for details. Sulfide consumption and sulfoxide yield, at selected reaction time, were taken as parameters to compare the reactivity of the various catalysts, the two values (see Tables) are equal within the experimental error $\pm 5 \%$. The data concerning the results with salophen complexes are collected in Table 1 whilst those related to salen species are in Table 2.

The Tables also contain the $\Sigma \sigma$ [42] which is the arithmetical sum of the $\sigma$ values for the substituents introduced into the salophen and salen scaffolds. These values are given to sketch out the electronic effect dictated by their presence. For the complexes used, it can be noted that, spanning from a $\Sigma \sigma$ of about +1 , due to the presence of four chlorine atoms, to a value of about -0.8 , when four $t$-butyl groups are present, a large variation of the electronic character of the metal ion, i.e. its Lewis acidity, should be obtained.

Looking at the data collected in the two tables some general comments can be done: the catalytic effect of the salophen and salen oxo vanadium $(\mathrm{V})$ complexes is quite good; the reaction times are short, most of the oxidations are complete in $15 \mathrm{~min}$ at room temperature. This last observation indicates that the vanadium catalyzed decomposition of $\mathrm{H}_{2} \mathrm{O}_{2}$ is not competing with the oxygen transfer reaction.

However (see Fig. 1), no simple correlation can be detected between the $\Sigma \sigma$ and the sulfoxide yields in both salophen and salen series; additionally, no simple comparison can be made in equally substituted couples of salophen and salen derivatives; this behavior being indeed expected on the basis of our previous studies [25].

Therefore, a deeper insight of the results is necessary in order to highlight, for each catalyst, if electronic or steric effects are playing the major role in determining the reactivity.

Interestingly, the catalytic activity of substituted salophen complexes, measured as sulfoxide yield at a specific reaction time (left graph), roughly follows the trend of the $\Sigma \sigma$ values with the exception of the $3,3^{\prime}-(\mathrm{OMe})_{2}$ derivative, this deviation from the expected result will be discussed below. The observed tendency apparently indicates that the reactivity somewhat follows the Lewis acidity character of vanadium, $\Sigma \sigma+0.9$ for $3,3^{\prime}, 5,5^{\prime}-\mathrm{Cl}_{4}$-salophen.

On the other hand, with substituted salen derivatives (right graph) no simple correlation can be established between the sulfoxide yields and the $\Sigma \sigma$ values; noteworthy, also in this series the $3,3^{\prime}-(\mathrm{OMe})_{2}$ derivative shows the highest reactivity. In addition, within this catalysts series high reactivity is observed with $5,5^{\prime}$ substituted ligands independently from their inductive effect, whereas for $3,3^{\prime}, 5,5^{\prime}$-tetra substituted species the reactivity appears to track the electron density around vanadium.

At this point of the discussion, a better understanding of the results obtained in the reactivity studies can be likely obtained looking also at the classical reaction mechanism [3-6,11] proposed for metal catalyzed sulfides oxidation with peroxides.

The accepted reaction mechanism for vanadium catalyzed oxidation processes with hydrogen peroxide requires the formation of a peroxide vanadium complex upon coordination of $\mathrm{H}_{2} \mathrm{O}_{2}$ to the 
Table 1

V-salophen $(0.00056 \mathrm{mmol})$ catalyzed oxidation of phenyl methyl sulfide $(0.059 \mathrm{mmol})$ with $\mathrm{H}_{2} \mathrm{O}_{2}(0.026 \mathrm{mmol})$ in $\mathrm{CH}_{3} \mathrm{CN}(5.33 \mathrm{ml})$ at room temperature.

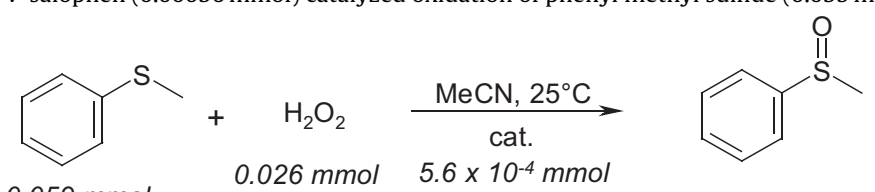

$0.059 \mathrm{mmol}$

\begin{tabular}{|c|c|c|c|c|c|}
\hline Catalyst & Substituent & $t, \min$ & \% Sulfide consumed & $\%$ Sulfoxide formed ${ }^{\mathrm{a}}$ & $\Sigma \sigma^{\mathrm{b}}$ \\
\hline & $3,3^{\prime}, 5,5^{\prime}-\mathrm{Cl}_{4}$ & $\begin{array}{r}2 \\
5 \\
15\end{array}$ & $\begin{array}{l}93 \\
93 \\
94\end{array}$ & $\begin{array}{l}94 \\
96 \\
94\end{array}$ & 0.908 \\
\hline
\end{tabular}<smiles></smiles>

$5,5^{\prime}-\mathrm{Cl}_{2}$

$\mathrm{H}$

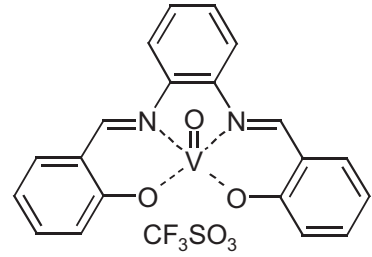<smiles></smiles>

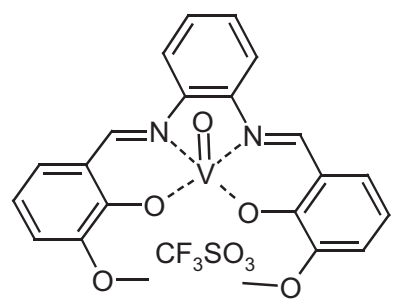<smiles></smiles>

87
91

92
94

92

$\begin{array}{lrrr} & 2 & 12 & 1.2 \\ 5,5^{\prime}-(t-B u)_{2} & 5 & 14 & 4.5\end{array}$




\begin{tabular}{|c|c|c|c|c|c|}
\hline Catalyst & Substituent & $t, \min$ & \% Sulfide consumed & \% Sulfoxide formed ${ }^{a}$ & $\Sigma \sigma^{\mathrm{b}}$ \\
\hline & & 2 & 18 & 0 & \\
\hline & $3,3^{\prime}, 5,5^{\prime}-(t-\mathrm{Bu})_{4}$ & 5 & 24 & 1.5 & -0.788 \\
\hline & & 15 & 20 & 6 & \\
\hline
\end{tabular}

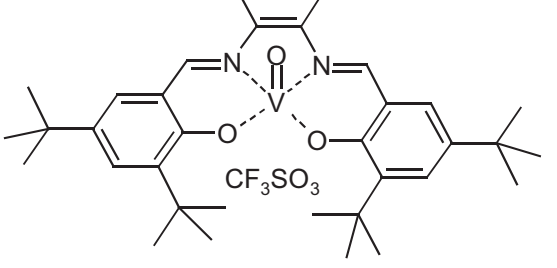

a Sulfide consumption and sulfoxide formation corresponds within the experimental error.

b $\Sigma \sigma$ is the arithmetical sum of all the $\sigma$ values [42].

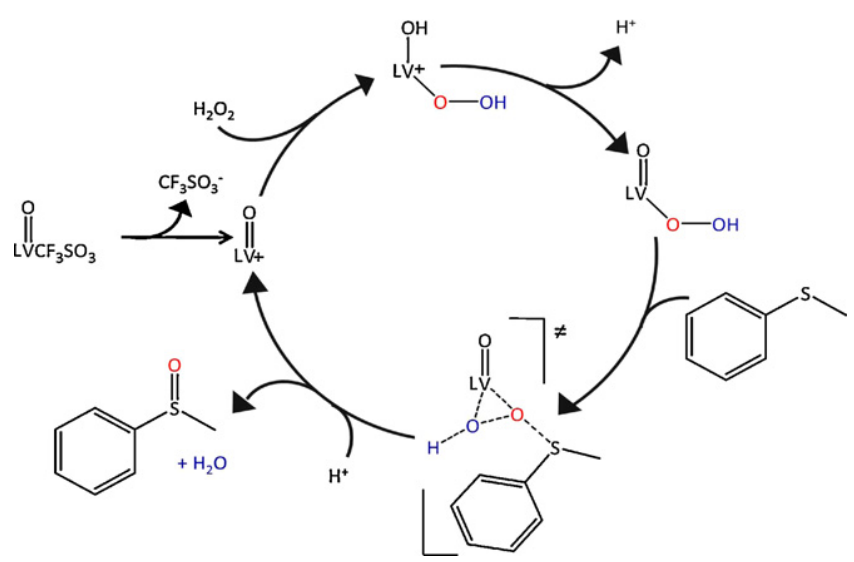

Scheme 2. Proposed catalytic cycle for sulfides oxidation with $\mathrm{H}_{2} \mathrm{O}_{2}$. L stands for salen or salophen derivatives.

metal center, such intermediate is then the bona fide oxidant of the substrate. For the sake of simplicity, we anticipate here that this active species likely is an hydroperoxo one. The coordination of the oxidant to the Lewis acid metal center activates the oxygen toward the nucleophilic attack of an electron rich substrate, such as the phenyl methyl sulfoxide. In the transition state of the oxidation step, coordination of the second peroxidic oxygen atom to vanadium helps the oxygen transfer to the substrate, subsequent elimination of the sulfoxide and a water molecule regenerates the catalyst precursor (Scheme 2).

With salophen and salen species formation of the peroxidic intermediate can be strongly influenced by the structure of the precursor. In order to consider this structural aspect, energy minimization of the peroxidic species, formed from salophen and salen $\mathrm{V}^{\mathrm{V}} \mathrm{O}$ precursors has been carried out and the outcome for the unsubstituted hydroperoxo oxovanadium complexes (the plausible active oxidant species) is shown in Fig. 2.

For example, salophen ligands force the precursor and the possible peroxo complexes in a planar conformation, i.e. the ligand resides on the plane of a simil-tetrahedrical shape (see Fig. 2a). On the other hand with salen ligands, together with the planar conformation (Fig. 2b) also a bent one can be adopted, in which one of the nitrogen of the ligand is trans to the oxo group (see Fig. 2c). It is interesting to note that from theoretical calculation (see following paragraphs), this latter conformation appears to be favorite. The gas phase optimized salenV $\mathrm{V}^{\mathrm{V}}(\mathrm{O})(\mathrm{OOH})$ and salophenV $\mathrm{V}(\mathrm{O})(\mathrm{OOH})$ structures show that the hydroperoxo group has a different approach to the metal depending on the conformation of the ligand. In particular, when the ligand has a planar conformation, like in the case of salophen $\mathrm{V}^{\mathrm{V}}(\mathrm{O})(\mathrm{OOH})$, the peroxo group almost adopt the sideon configuration around the metal, thus facilitating the oxygen transfer to the substrate. On the contrary, when the ligand has a bent conformation, like in the case of $\operatorname{salenV}^{\mathrm{V}}(\mathrm{O})(\mathrm{OOH})$ (see Fig. 2c) the approach of the second oxygen to the metal is hampered as shown by the longer distance in the calculated structure, thus preventing the stabilization of the transition state.

Summarizing, theoretical calculations suggest that salophen ligands force the hydroperoxovanadium complex in a planar conformation that allows the stabilization of the transition state of the oxidation step, resulting in a higher reactivity with respect to salen complexes, where the more stable bent conformation can be adopted.

Returning to the experimental data, the higher reactivity of the salophen derivatives, together with the observed relationship of the sulfoxide yields with the Lewis acid character of the vanadium center, appears to be related to the planar arrangement of such species which in turn is dictated by the structure of the ligands. On the other hand, with salen derivatives, which can adopt several different conformations because of the mobility of the ligand, the steric hindrance of the substituents combines, in an unpredictable way, with the electronic character of the catalyst.

The 3,3' dimethoxy substituted salophen and salen oxovanadium complexes deserve a specific discussion. In fact, the

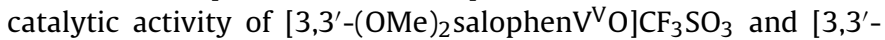
$(\mathrm{OMe})_{2}$ salenV $\left.^{\mathrm{V}} \mathrm{O}\right] \mathrm{CF}_{3} \mathrm{SO}_{3}$ is much higher than that of all the other derivatives in the corresponding series (see Fig. 1). This behavior may suggest an easier formation of the metalperoxide species. In that respect, as indicated in Fig. 3, the presence of 3,3'-(OMe $)_{2}$ substituents may stabilize the approach of $\mathrm{a}_{2} \mathrm{O}_{2}$ molecule to the metal center, through the intervention of an hydrogen bond.

\subsection{2. ${ }^{51} \mathrm{~V}$ NMR studies}

It is well known that the number and the nature of the peroxometal species strongly depends on the reaction conditions, such as the $\mathrm{pH}$ value, the ligand and the solvent. Since it is not always possible to obtain peroxovanadium complexes in the solid state, and often their solution structure is different, their structure is often investigated by means of several techniques. For example, ${ }^{51} \mathrm{~V}$ NMR and electrospray ionization mass spectrometry (ESI-MS) or theoretical calculations have been recently used in order to understand their behavior in catalytic cycles [43].

The most common structures of monoperoxovanadium complexes are the side-on cyclic peroxo species, in which both the oxygen atoms are coordinated to vanadium atom, and the hydroperoxo species, in which only one oxygen is covalently linked to the metal center. In this work we have tried to obtain information on the formation in solution of the peroxo derivatives from salophen and/or salen $\mathrm{V}(\mathrm{V})$ species, in the presence of different excesses of hydrogen peroxide. ${ }^{51} \mathrm{~V}$ NMR spectra have been acquired for some of the vanadium $(\mathrm{V})$ precursors in acetonitrile and, in all cases, single peaks appeared around $-600 \mathrm{ppm}$. To note, 
Table 2

V-salen $(0.00056 \mathrm{mmol})$ catalyzed oxidation of phenyl methyl sulfide $(0.059 \mathrm{mmol})$ with $\mathrm{H}_{2} \mathrm{O}_{2}(0.026 \mathrm{mmol})$ in $\mathrm{CH}_{3} \mathrm{CN}(5.33 \mathrm{ml})$ at room temperature.

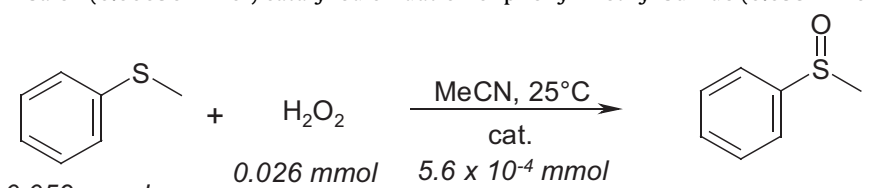

$0.059 \mathrm{mmol}$

Catalyst

Substituents

$t, \min$

\% Sulfide consumed

$\%$ Sulfoxide formed

$\Sigma \sigma^{\mathrm{b}}$

$3,3^{\prime}, 5,5^{\prime}-\mathrm{Cl}_{4}$

2
5
15<smiles></smiles>

$5,5^{\prime}-\mathrm{Cl}_{2}$

$\begin{array}{rrr}2 & 76 & 76 \\ 5 & 98 & 99 \\ 15 & 96 & 98\end{array}$

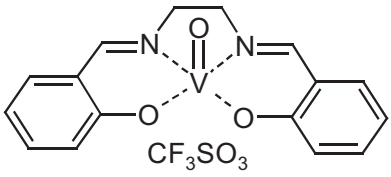

$\mathrm{H}$

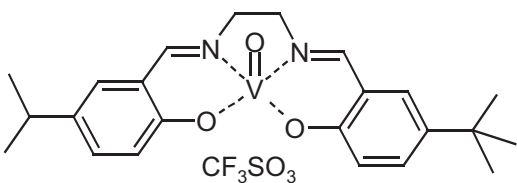

$5,5^{\prime}-(t-B u)$

88

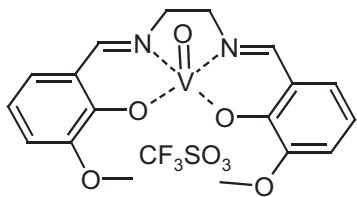

3,3'-(OMe)

$>99$

$>99$

$>99$

$-0.536$<smiles></smiles>

$5,5^{\prime}-(\mathrm{OMe})_{2}$

2
5
15

34

62

$-0.536$

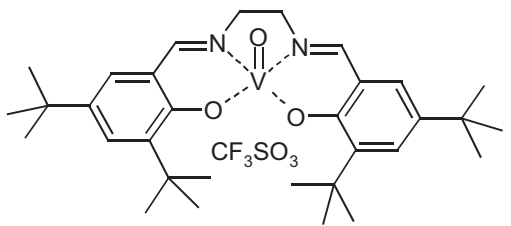

$3,3^{\prime}, 5,5^{\prime}-(t-\mathrm{Bu})_{4}$

$\begin{array}{rr}2 & 92 \\ 5 & 88 \\ 15 & 92\end{array}$



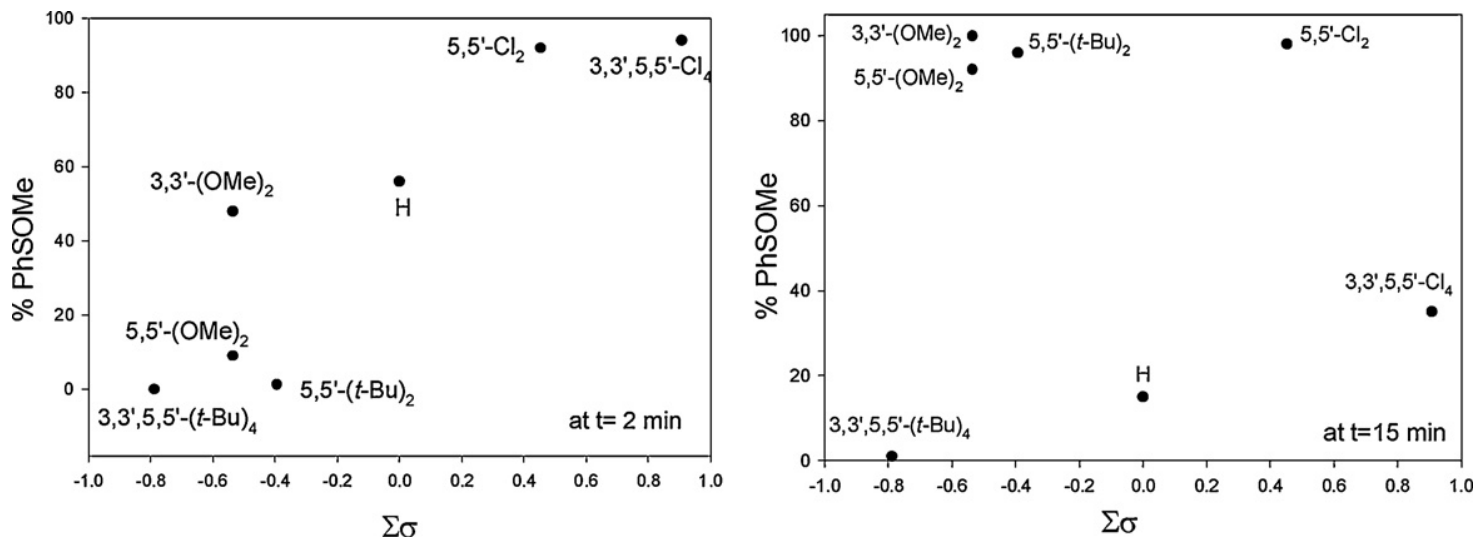

Fig. 1. PhSOMe yields $v s$. $\Sigma \sigma$ of the ligands. Left: V-salophen catalyzed oxidation of PhSMe with $\mathrm{H}_{2} \mathrm{O}_{2}$ in $\mathrm{CH}_{3} \mathrm{CN}$ at room temperature at 2 min (experimental conditions reported in Table 1). Right: $\mathrm{V}$-salen catalyzed oxidation of $\mathrm{PhSMe}$ with $\mathrm{H}_{2} \mathrm{O}_{2}$ in $\mathrm{CH}_{3} \mathrm{CN}$ at room temperature at 15 min (experimental conditions reported in Table 2).

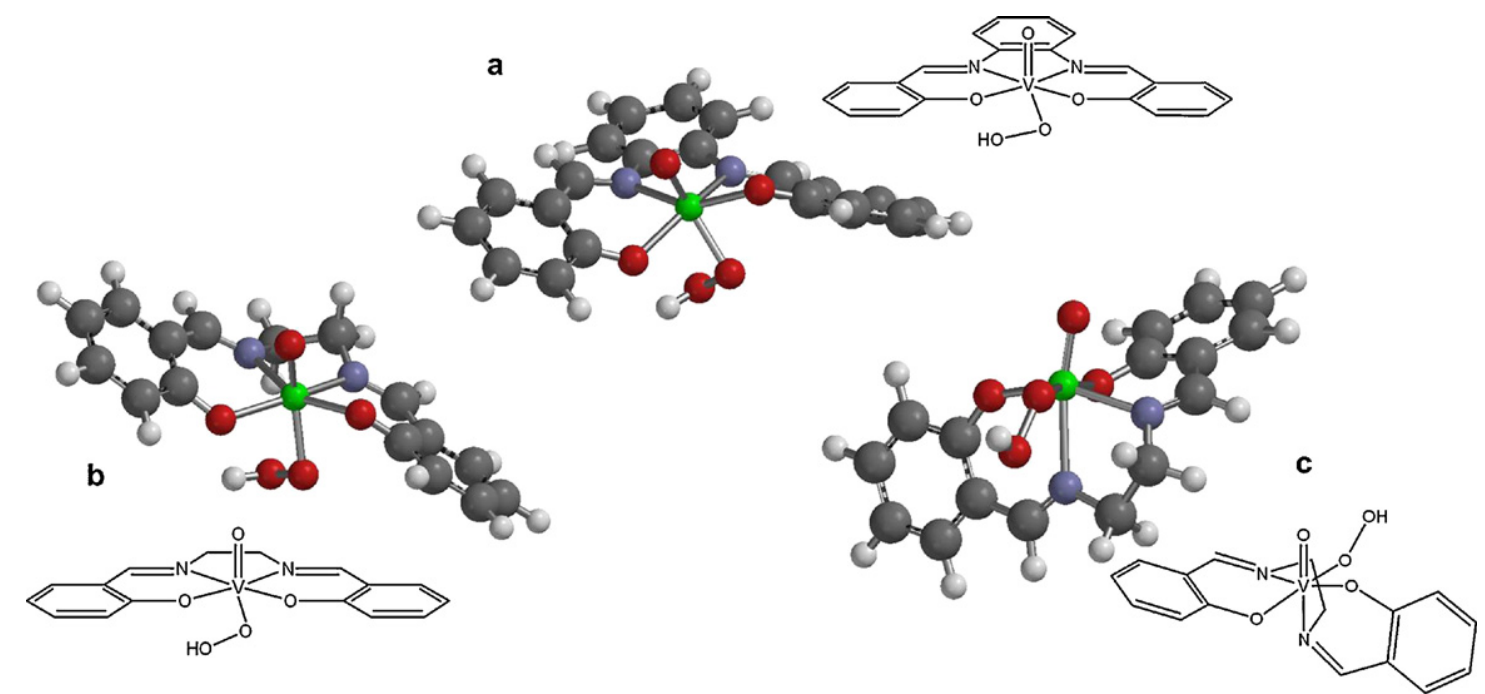

Fig. 2. Gas phase optimized structures of $\mathrm{LV}^{\mathrm{V}}(\mathrm{O})(\mathrm{OOH})$ complexes $(\mathrm{L}=$ salen or salophen). (a) Planar conformation of salenV $(\mathrm{O})(\mathrm{OOH})$. (b) Planar conformation of salophenV $(\mathrm{O})(\mathrm{OOH})$. (c) Bent conformation of $\operatorname{salenV}^{\mathrm{V}}(\mathrm{O})(\mathrm{OOH})$.

the chemical shifts for salen and salophen species are very similar, despite of the presence of different substituents on the aromatic scaffold.

Upon addition of increasing amounts of $\mathrm{H}_{2} \mathrm{O}_{2}$ to a solution of [salophen $\mathrm{V}^{\mathrm{V}} \mathrm{O}_{\mathrm{C}} \mathrm{CF}_{3} \mathrm{SO}_{3}$ or $\left[\right.$ salenV ${ }^{\mathrm{V}} \mathrm{O}_{\mathrm{C}} \mathrm{CF}_{3} \mathrm{SO}_{3}$, the signal of the precursor decreases and, for both complexes, no signals appear having reference to vanadium free ligand species; in general, no other ${ }^{51} \mathrm{~V}$ signals were present in NMR spectra different from that of the

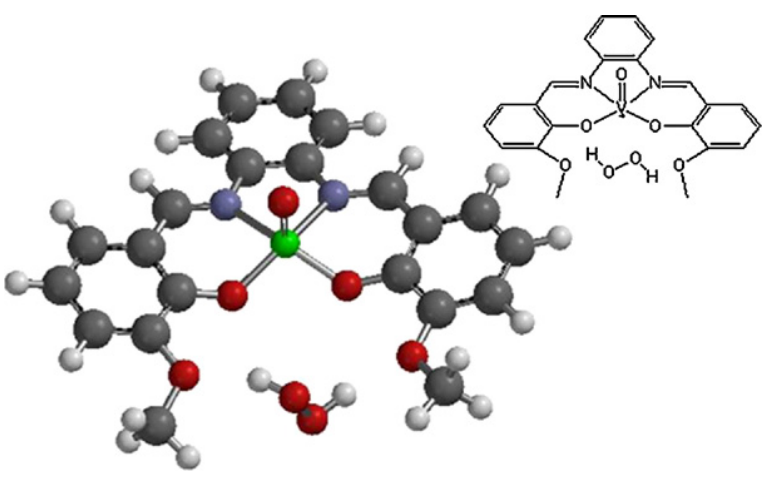

Fig. 3. Plausible formation of an hydrogen bond between an approaching $\mathrm{H}_{2} \mathrm{O}_{2}$ molecule and the methoxy oxygens in $\left[3,3^{\prime}-(\mathrm{OMe})_{2}\right.$ salophenV $\left.\mathrm{V}^{\mathrm{V}} \mathrm{O}\right] \mathrm{CF}_{3} \mathrm{SO}_{3}$ complex. catalyst precursor, over a wide range of chemical shift (as an example, see Fig. 4 for [ salenV $^{\mathrm{V}} \mathrm{O}_{\mathrm{C}} \mathrm{CF}_{3} \mathrm{SO}_{3}$ ). Peroxovanadium species usually give signals at high fields [44]; in this case, the absence of any signal may be due to the low solubility of peroxometal species at room temperature. In fact, the formation of a yellow precipitate was observed upon addition of a large excess of $\mathrm{H}_{2} \mathrm{O}_{2}$ to a solution of salenVO ${ }^{+}$in acetonitrile.

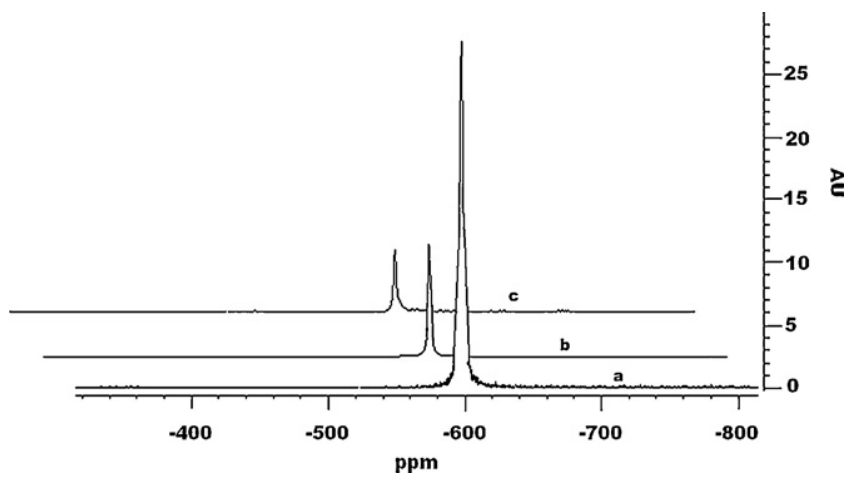

Fig. 4. ${ }^{51} \mathrm{~V}$ NMR spectra of $\left[\right.$ SalenV $\left.{ }^{\mathrm{V}} \mathrm{O}\right] \mathrm{CF}_{3} \mathrm{SO}_{3}$ in acetonitrile $(1 \mathrm{mM})$. (a) Initial solution (b) after addition of 2 equivalents of $\mathrm{H}_{2} \mathrm{O}_{2}$ to the previous solution; (c) after addition of 160 equivalents of $\mathrm{H}_{2} \mathrm{O}_{2}$ to the initial solution. 
Table 3

${ }^{51} \mathrm{~V}$ NMR chemical shifts for $\operatorname{different}(\mathrm{V})$ complexes in $\mathrm{CH}_{3} \mathrm{CN}$.

\begin{tabular}{|c|c|}
\hline Catalyst & $\delta{ }^{51} \mathrm{~V}$ NMR $(\mathrm{ppm})$ \\
\hline $\begin{array}{l}{\left[\text { salenV}^{\mathrm{V}} \mathrm{O}\right] \mathrm{CF}_{3} \mathrm{SO}_{3}} \\
{\left[5,5^{\prime}-(\mathrm{Cl})_{2} \text { salenVV }^{\mathrm{V}} \mathrm{O}_{\mathrm{CF}_{3}} \mathrm{SO}_{3}\right.} \\
{\left[5,5^{\prime}-(t-\mathrm{Bu})_{2} \mathrm{salenV}^{\mathrm{V}} \mathrm{O}\right] \mathrm{CF}_{3} \mathrm{SO}_{3}} \\
{\left[\text { salophenV } \mathrm{O}^{\mathrm{V}} \mathrm{CF}_{3} \mathrm{SO}_{3}\right.} \\
{\left[3,3^{\prime}, 5,5^{\prime}-(t-\mathrm{Bu})_{4} \text { salophenV }^{\mathrm{V}} \mathrm{O}_{\mathrm{CF}_{3}} \mathrm{SO}_{3}\right.}\end{array}$ & $\begin{array}{l}-597 \\
-596 \\
-584 \\
-604 \\
-595\end{array}$ \\
\hline
\end{tabular}

The IR spectrum of the yellow precipitate showed no signals in the range of $918-954 \mathrm{~cm}^{-1}$ were the $0-0$ stretching is usually present for side-on monoperoxo vanadium complexes [12], thus supporting the hypothesis that salen and salophen oxovanadium complexes form an end-on hydroperoxidic species in the presence of $\mathrm{H}_{2} \mathrm{O}_{2}$ (see Section 3 below).

When salen $\mathrm{V}^{\mathrm{V}} \mathrm{OBr}$ was used as precursor, ${ }^{51} \mathrm{~V}$ NMR spectra in the presence of increasing amount of hydrogen peroxide showed disappearance of the signal at $-595 \mathrm{ppm}$, already after the addition of ten equivalents of $\mathrm{H}_{2} \mathrm{O}_{2}$. In this conditions no formation of the yellow precipitate was observed. This suggests that the formation of the peroxovanadium species is more favorable when the less tightly coordinated $\mathrm{Br}^{-}$is the counterion in place of $\mathrm{CF}_{3} \mathrm{SO}_{3}{ }^{-}$. In agreement with such observation, when salen $\mathrm{V}^{\mathrm{V}} \mathrm{OBr}$ was tested as catalyst, a faster decomposition of hydrogen peroxide is observed $[5,26]$.

\subsubsection{Theoretical studies}

The unclear results obtained with the NMR spectroscopy prompted us to apply DFT theoretical calculations (see Section 2.1 for details) in order to shed more light on the structure of the reactive peroxo complexes formed in solution, when salophen and salen vanadium $(\mathrm{V})$ precursors are used.

Therefore, calculation on relevant species were performed at B3LYP/lanl2dz level, including solvent effects with the IEF-PCM method (acetonitrile). These include vanadium hydroperoxides and $\eta^{2}$ peroxides, in different protonation forms, and in the presence of a residual oxo or hydroxo ligand (Scheme 3). Frequency calculations were performed in order to confirm that the equilibrium structures were actual minimum energy species (Table 3 ).

Optimized distances between the vanadium center and the coordinated oxygen of the peroxide moiety fall in the range $1.82-2.05 \AA$, while oxygen-oxygen distances of the peroxide group are found between 1.46-1.51 $\AA$; both are in good agreement with literature values $[45,46]$. In general, a decrease of the $\mathrm{V}-\mathrm{O}(\mathrm{O})$ distance is observed increasing the positive charge of the species $[45,46]$. When the peroxide is protonated (vanadium hydroperoxides), the protonated oxygen is not located at binding distance from the vanadium center, confirming a monodentate mode of coordination of the $\mathrm{O}-\mathrm{O}$ group to the metal; differently, when the peroxide moiety is not protonated both oxygen atoms are coordinated to vanadium, in a $\eta^{2}$ mode [47].

As illustrated in Fig. 2, only planar conformations were considered for salophen complexes, while bent and planar conformations were explored for all the salen $V^{\mathrm{V}}$ species. To note, as reported in Table 4 , some of the salenV $V^{V}$ derivatives are more stable in the bent conformation, and in particular the $\mathrm{V}(\mathrm{O})(\mathrm{OOH})$ peroxo complex, which is the reasonable active species responsible for oxygen transfer (vide infra).

The accepted mechanism, already proposed in the literature, for the formation of peroxidic species resulting from the reaction of vanadium species with hydrogen peroxide $[43,45,46]$ has been used as the base to analyze the energetic path leading to the formation of the peroxo species possibly responsible for oxygen transfer, see Scheme 4.
Table 4

Energetically preferred conformations for salenV $V^{\mathrm{V}}$ complexes as derived by DFT calculations.

\begin{tabular}{lllc}
\hline salenV $^{\mathrm{V}}$ complex & Bent & Planar & $\Delta G^{\mathrm{a}}\left(\mathrm{kcal} \mathrm{mol}^{-1}\right)$ \\
\hline$\left[\text { salenV }^{\mathrm{V}}(\mathrm{OH})(\underline{\mathrm{OOH}})\right]^{+}$ & & $\times$ & 2.3 \\
{$\left[\operatorname{salenV}^{\mathrm{O}}(\underline{\mathrm{OOH}})\right]$} & $\times$ & & 6.7 \\
{$\left[\operatorname{salenV}^{\mathrm{O}}(\underline{\mathrm{OO}})(\mathrm{OH})\right]$} & & $\times$ & 1.0 \\
{$\left[\text { salenV }^{\mathrm{O}}(\underline{\underline{\mathrm{OO}}})\right]^{-}$} & $\times$ & & 14.6 \\
\hline
\end{tabular}

a Free energy difference between most and less stable conformations for each species.

In such scheme the original state of the catalyst was considered to be a $\mathrm{LV}^{\mathrm{V}} \mathrm{O}^{+}$species ( $\mathrm{L}$ stands for salen or salophen ligand) originated from dissociation of $\mathrm{LV}^{\mathrm{V}} \mathrm{OCF}_{3} \mathrm{SO}_{3}$ in solution; addition of $\mathrm{H}_{2} \mathrm{O}_{2}$ to $\mathrm{LV}^{\mathrm{V}} \mathrm{O}^{+}$to form $\mathrm{LV}^{\mathrm{V}}(\mathrm{OH})(\mathrm{OOH})^{+}$species were found to be endothermic processes, with $\Delta G=+18.1$ and $+21.4 \mathrm{kcal} \mathrm{mol}^{-1}$ for $\mathrm{L}=$ salen and salophen, respectively. For this reason, and considering also the steric hindrance of the ligands around the metal, only the formation of monoperoxo species was taken into account. Moreover, the fact that addition of $\mathrm{H}_{2} \mathrm{O}_{2}$ are endoergonic processes, suggest that only small amounts of vanadium peroxo complexes form in solution; this result is consistent with ${ }^{51} \mathrm{~V}$ NMR spectra, where no signals different from the one of the precursor have been detected.

Subsequent calculations were aimed at establishing the reactivity of the $\mathrm{LV}^{\mathrm{V}}(\mathrm{OH})(\mathrm{OOH})^{+}$species. A crucial observation is that such intermediates behave as strong acids, by releasing a proton from the hydroxo group to form $\operatorname{LV}^{\mathrm{V}}(\mathrm{O})(\mathrm{OOH}$ ) derivatives (deprotonation step in Scheme 4). This resulted by calculation of the $p K a$ of the species, by comparison with a reference acid/base couple according to Wang et al. [48]. This procedure avoids direct calculation on $\mathrm{H}_{3} \mathrm{O}^{+}$ species, that are subject to relevant solvent effects, difficult to evaluate employing a continuum approximation. In this particular case, the pyridinium/pyridine couple $(p K a=5.25)$ was chosen as the reference, in order to maintain the same total charge of the acid/base couple under investigation, $\operatorname{LV}^{V}(\mathrm{OH})(\mathrm{OOH})^{+} / \mathrm{LV}^{\mathrm{V}}(\mathrm{O})(\mathrm{OOH})$.

Calculated $p K a$ for the $\mathrm{LV}^{\mathrm{V}}(\mathrm{OH})(\mathrm{OOH})^{+} / \mathrm{LV}^{\mathrm{V}}(\mathrm{O})(\mathrm{OOH})$ couples were found -6.9 and -4.6 for salen and salophen derivatives, respectively, thus confirming high acid behavior of the hydroxo group coordinated to the vanadium center.

The $\mathrm{LV}^{\mathrm{V}}(\mathrm{O})(\mathrm{OOH})$ species were confirmed to be the most probable ones, since possible isomers were observed at higher energy. Indeed, $\operatorname{LV}^{\mathrm{V}}(\mathrm{OH})(\mathrm{OO})$ species are higher in energy by 12.5 and $4.1 \mathrm{kcal} \mathrm{mol}^{-1}$ for salen and salophen, respectively, while a $\mathrm{H}_{-} \mathrm{LV}^{\mathrm{V}}(\mathrm{O})(\mathrm{OO})$ derivative (where the proton is located at the oxygen atom of the $\mathrm{L}$ ligand) is $2.2-8.7 \mathrm{kcal} \mathrm{mol}^{-1}$ higher when $\mathrm{L}=$ salophen (the same structure with $\mathrm{L}=$ salen failed to converge). Protonation of the peroxide species, with no involvement of the oxo group, was recently demonstrated by XANES spectroscopy for a [HheidaV $(\mathrm{O})(\mathrm{OO})]^{-}$complex (heida $=\mathrm{N}-(2-$ hydroxyethyl)iminodiacetic acid) to be the key step to activate the species for oxygen transfer catalysis [49].

An alternative pathway (not represented in Scheme 4), where water elimination from the $\operatorname{LV}^{V}(\mathrm{OH})(\mathrm{OOH})^{+}$leads to the formation of a $\mathrm{LV}^{\mathrm{V}}(\mathrm{OO})^{+}$species was found to be endothermic by $5.4 \mathrm{kcal} \mathrm{mol}^{-1}$ in the case of $\mathrm{L}=$ salen, confirming that vanadium complexes without oxo or hydroxo moieties are not stable [12]:

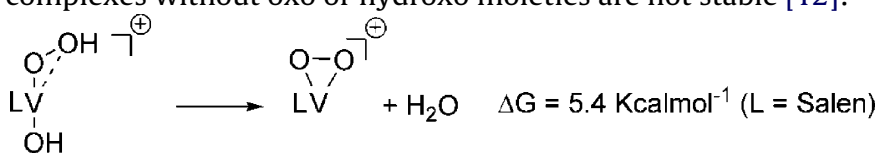

Therefore, calculations suggest that a vanadium oxohydroperoxo species, $\operatorname{LV}^{\mathrm{V}}(\mathrm{O})(\mathrm{OOH})$, is the most plausible intermediate formed upon $\mathrm{H}_{2} \mathrm{O}_{2}$ addition to vanadium Salen and Salophen complexes, followed by one proton removal. A 

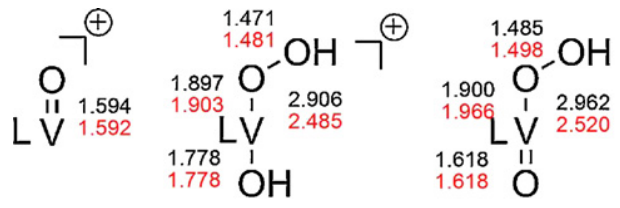

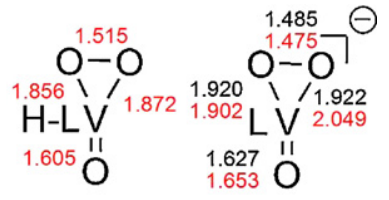

\section{$\mathrm{L}=$ Salen or Salophen}

Scheme 3. Representation of relevant species considered in DFT calculations, with optimized interatomic distances indicated in black and red for salen and salophen species, respectively. The salen or salophen ligand is represented as "L" for clarity reasons.

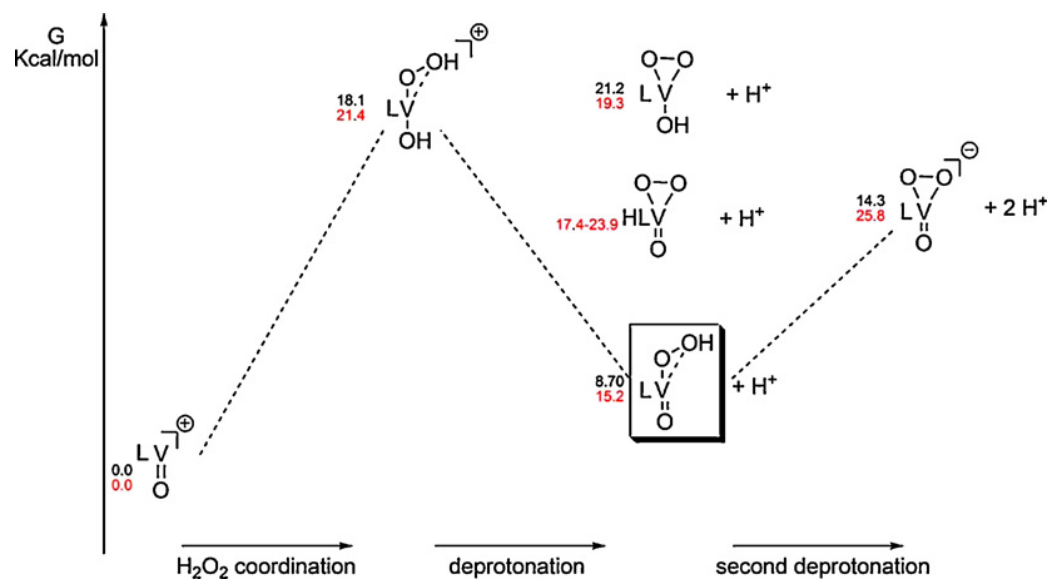

Scheme 4. Energies for the formation pathways of various vanadium based peroxo complexes with L=salen (black values) or salophen (red values). The energy of the reactions involving $\mathrm{H}^{+}$ions were not directly calculated, but determined indirectly from the calculation of the $p K a$ of the competent species. (For interpretation of the references to color in this figure legend, the reader is referred to the web version of the article.)

potential, second deprotonation of $\mathrm{LV}^{\mathrm{V}}(\mathrm{O})(\mathrm{OOH})$ to give an anionic $\mathrm{LV}^{\mathrm{V}}(\mathrm{O})(\mathrm{OO})^{-}$species was also considered; in these cases calculated pKa are 4.1 and 7.8 for $\mathrm{L}=$ salen and salophen, respectively (in this case acetic acid/acetate has been used as the reference acid/base couple, in order to preserve the charges of the species in the equilibrium process). It is interesting to notice that the calculated $p K a$ compare reasonably with the values of 5.4-5.9 observed for the vanadium-dependent haloperoxidases enzymes [50,51]. Nevertheless, deprotonated peroxides such as $\mathrm{LV}^{\mathrm{V}}(\mathrm{O})(\mathrm{OO})^{-}$are known to be poorly active in oxygen transfer $[45,46,49]$, therefore, even if they could actually be formed in solution according to the $\mathrm{pKa}$ values discussed above, they are not the reasonable catalytically active species in the present system.

Therefore, the presence of the $\operatorname{LV}^{\mathrm{V}}(\mathrm{O})(\mathrm{OOH})$ peroxo complexes in solution is the most reliable scenario. This is in agreement with results found in the literature for similar vanadium complexes with model salan ligands [52], where the oxo hydroperoxo vanadium derivatives appears to be the most favorable active species in alkene epoxidation processes. In such paper, the salan ligand is coordinated to $\mathrm{V}$ atom in a bent conformation, in which two $\mathrm{O}$ and one $\mathrm{N}$ occupy the equatorial positions, while the remaining $\mathrm{O}$ is in the axial one; this conformation is consistent with the bent arrangement of the ligand around the vanadium atom that we found for salenVO peroxo complexes.

In the case of salenV $(\mathrm{O})(\mathrm{OOH})$ peroxocomplex, the energies for the bent and planar conformations of all the 5,5'-substituted derivatives were calculated in the gas phase in order to understand whether the presence of substituents could affect their conformations. The comparison between the two conformations, represented by their energy differences, is reported in Table 5 . Interestingly, in all cases the most favorable structure is the bent one. For the unsubstituted salen complex, energies in acetonitrile as the model solvent were evaluated, obtaining comparable results.
A final argument concerns the possible oxygen transfer activity of these $\operatorname{LV}(\mathrm{O})(\mathrm{OOH})$ peroxides, namely if they can be the actual species responsible for sulfide oxidation.

As discussed above, the optimized geometries of $\operatorname{LV}(\mathrm{O})(\mathrm{OOH})$ peroxides strongly suggest a monodentate binding of the peroxide to the vanadium center, and it occurs with the non protonated peroxidic oxygen, while the protonated oxygen is not located at binding distance from the vanadium $(\mathrm{V}-\mathrm{O}(\mathrm{H})=2.962 \AA$ and $2.520 \AA$ for $\mathrm{L}=$ salen and salophen, respectively). This differs from other vanadium hydroperoxo species reported in the literature, where the calculated $\mathrm{V}-\mathrm{O}(\mathrm{H})$ distance is much shorter $[45,46]$ and can be related to the higher steric hindrance of salen and salophen ligands.

As a result, two different scenario can be envisaged: (a) the $\mathrm{LV}(\mathrm{O})(\mathrm{OOH})$ are the actual species for oxygen transfer; indeed the $\mathrm{O}-\mathrm{O} \sigma^{*}$ orbitals, usually recognized as the one giving the most important contribution in the electrophilic oxidative activity of metal peroxides [53-55], are found at reasonable energy levels for both species (Fig. 5); (b) the $\operatorname{LV}(\mathrm{O})(\mathrm{OOH}$ ) species are in equilibrium with other forms, where also the second protonated oxygen is coordinated to vanadium, and these latter species are responsible for oxygen transfer:

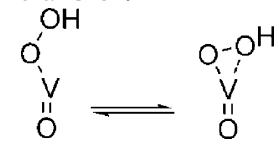

Table 5

Differences of energies for planar and bent conformations of differently substituted salenV $(\mathrm{O})(\mathrm{OOH})$ species.

\begin{tabular}{ll}
\hline salenV $(\mathrm{O})(\mathrm{OOH})$ complex & $\Delta E$ (bent-planar $)\left(\mathrm{kcal} \mathrm{mol}^{-1}\right)$ \\
\hline$\left[5,5^{\prime}-(\mathrm{t}-\mathrm{Bu})_{2}\right.$ salenV $\left.\mathrm{V}^{\mathrm{O}}(\mathrm{OOH})\right]$ & -7.71 \\
{$\left[5,5^{\prime}-(\mathrm{MeO})_{2}\right.$ salenV $\left.\mathrm{V}^{\mathrm{O}} \mathrm{O}(\mathrm{OOH})\right]$} & -8.79 \\
{$\left[\right.$ salenV $\left.^{\mathrm{O}} \mathrm{O}(\mathrm{OOH})\right]$} & $-7.46\left(-6.7\right.$ in $\left.\mathrm{CH}_{3} \mathrm{CN}\right)$ \\
{$\left[5,5^{\prime}-(\mathrm{Cl})_{2}\right.$ salenV $\left.\mathrm{O}(\mathrm{OOH})\right]$} & -7.84 \\
\hline
\end{tabular}




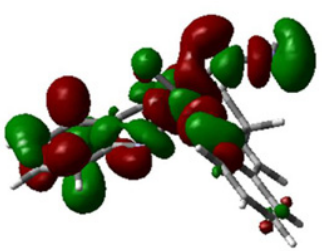

$\mathrm{E}=-0.028$ a.u.

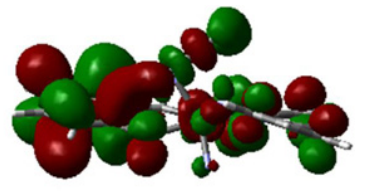

$\mathrm{E}=-0.007$ a.u.
Fig. 5. Representation of the $\mathrm{O}-\mathrm{O} \sigma^{*}$ orbital for $\operatorname{SalenV}(\mathrm{O})(\mathrm{OOH})(\mathrm{LUMO}+6)$ and SalophenV $(\mathrm{O})(\mathrm{OOH})(\mathrm{LUMO}+10)$ species.

Equilibria of this type have already been considered for other $\mathrm{V}(\mathrm{V})$ species, where the $\eta^{2}$ coordination of the hydroperoxide was necessary to observe oxygen transfer activity and the free energy of the reaction was influenced by the presence of Lewis bases as coligands [56]. Equilibria of this type are currently under evaluation for salen and salophen derivatives. However, being the distance of the protonated oxygen shorter in the salophen complexes, they may likely establish more easily such equilibrium. On this basis the higher activity of salophen complexes with respect to salen ones could be explained, further support to this is given by their observed higher Lewis acidity as measured with CV experiments [37].

Full mechanistic study, including evaluation of transition states, is in progress and will be reported in a separate communication.

\section{Conclusions}

The experimental and theoretical results obtained, even though do not allow to draw a decisive picture of the mechanism, let to emphasize that steric factors play a major role in determining the outcome of the reaction, often overcoming the electronic effects. Theoretical results suggest the intervention in the catalytic cycle of an hydroperoxo vanadium species.

\section{Acknowledgements}

Research carried out in the framework of COST D40 Action "Innovative Catalysis - New Processes and Selectivities". Experimental work of S. Ummarino and G. Di Carmine is acknowledged.

\section{Appendix A. Supplementary data}

Supplementary data associated with this article can be found, in the online version, at http://dx.doi.org/10.1016/ j.cattod.2012.03.032.

\section{References}

[1] T. Punniyamurthy, S. Velusamy, J. Ikbal, Chemical Reviews 105 (2005) 2329-2363.

[2] P.T. Anastas, J.T. Warner, Green Chemistry Theory and Practice, Oxford University Press, 1998.

[3] R.A. Sheldon, I. Arends, U. Hanefeld, Green Chemistry and Catalysis, Wiley-VCH, Weinheim, Germany, 2007.

[4] G. Strukul, Catalytic Oxidation with Hydrogen Peroxide as Oxidant, Kluwer Academic Publisher, Netherlands, 1992.

[5] V. Conte, B. Floris, Inorganica Chimica Acta 363 (2010) 1935-1946, and references therein.

[6] V. Conte, A. Coletti, B. Floris, G. Licini, C. Zonta, Coordination Chemistry Reviews 255 (2011) 2165-2177, and references therein.

[7] G. Licini, V. Conte, A. Coletti, M. Mba, C. Zonta, Coordination Chemistry Reviews 255 (2011) 2345-2357, and references therein.

[8] A. Butler, Coordination Chemistry Reviews 187 (1999) 17-35, and refs. cited therein.

[9] V.M. Dembitsky, Tetrahedron 59 (2003) 4701-4720.

[10] A.G.J. Ligtenbarg, R. Hage, B.L. Feringa, Coordination Chemistry Reviews 237 (2003) 89-101
[11] V. Conte, O. Bortolini, in: Z. Rappoport (Ed.), The Chemistry of Peroxides Transition Metal Peroxides Synthesis and Role in Oxidation Reactions, Wiley Interscience, 2006, pp. 1053-1128.

[12] V. Conte, B. Floris, Dalton Transactions 40 (2011) 1419-1436, and references therein.

[13] M.L. Ramos, L.L.G. Justino, H.D. Burrows, Dalton Transactions 40 (2011) 4374-4383, and references therein.

[14] See as an example M.V. Kirillova, M.L. Kuznetsov, V.B. Romakh, L.S. Shul'pina, J.J.R. Fráusto da Silva, A.J.L. Pombeiro, G.B. Shul'pin., Journal of Catalysis 267 (2009) 140-167.

[15] D.C. Crans, J.J. Smee, E. Gaidamauskas, L. Yang, Chemical Reviews 104 (2004) 849-902.

[16] J.A.L. da Silva, J.J.R. Frausto da Silva, A.J.L. Pombeiro, Coordination Chemistry Reviews 255 (2011) 2232-2248.

[17] C. Bolm, Coordination Chemistry Reviews 237 (2003) 245-256.

[18] E. Wojaczyska, J. Wojaczyski, Chemical Reviews 110 (2010) 4303-4356.

[19] J. Gätjens, B. Meier, Y. Adach, H. Sakurai, D. Rehder, European Journal of Inorganic Chemistry (2006) 3575-3585.

[20] C. Song, Catalysis Today 86 (2003) 211-263.

[21] P.S. Kulkarni, C.A.M. Afonso, Greem Chemistry 12 (2010) 1139-1149.

[22] P.G. Cozzi, Chemical Society Reviews 33 (2004) 410-421.

[23] A. Zulauf, M. Mellah, X. Hong, E. Schulz, Dalton Transactions 39 (2010) 6911-6935.

[24] P. Adão, M.R. Maurya, U. Kumar, F. Avecilla, R.T. Henriques, M.L. Kusnetsov, J. Costa Pessoa, I. Correia, Pure and Applied Chemistry 81 (2009) 1279-1296.

[25] V. Conte, F. Fabbianesi, B. Floris, P. Galloni, D. Sordi, I.W.C.E. Arends, M. Bonchio D. Rehder, D. Bogdal, Pure and Applied Chemistry 81 (2009) 1265-1277.

[26] M. Bonchio, V. Conte, F. Di Furia, G. Modena, S. Moro, J.O. Edwards, Inorganic Chemistry 33 (1994) 1631-1637.

[27] C.P. Horwitz, P.J. Winslow, J.T. Warden, C.A. Lisek, Inorganic Chemistry 32 (1993) 82-88.

[28] N.F. Choudhary, N.G. Connelly, P.B. Hitchcock, G.J. Leigh, Journal of the Chemical Society, Dalton Transactions (1999) 4437-4446.

[29] M.P. Webereski Jr., C.C. McLauchlan, C.G. Hamaker, Polyhedron 25 (2006) 119-123.

[30] A.L. Singer, D.A. Atwood, Inorganica Chimica Acta 277 (1998) 157-162.

[31] C.J. Chang, J.A. Labinger, H.B. Gray, Inorganic Chemistry 36 (1997) 5927-5930.

[32] J.A. Bonadies, C.J. Carrano, Journal of the American Chemical Society 108 (1986) 4088-4095.

[33] M. Salavati-Niasari, A. Badiei, K. Saberyan, Chemical Engineering Journal 173 (2011) 651-658.

[34] E. Tsuchida, K. Yamamoto, K. Oyaizu, N. Iwasaki, F.C. Anson, Inorganic Chemistry 33 (1994) 1056-1063.

[35] T. Ben, I. Zid, A. Keheder, Ghorbel, Reaction Kinetics Mechanisms 100 (2010) $131-143$.

[36] J. Zhao, W. Wang, Y. Zhang, Journal of Inorganic and Organometallic Polymers 18 (2008) 441-447.

[37] A. Coletti, C.J. Whiteoak, V. Conte, A.W. Kleij, ChemCatChem 4 (2012), http://dx.doi.org/10.1002/cctc.201100398.

[38] M.J. Frisch, G.W. Trucks, H.B. Schlegel, G.E. Scuseria, M.A. Rob, J.R. Cheeseman, J.A. Montgomery Jr., T. Vreven, K.N. Kudin, J.C. Burant, J.M. Millam, S.S. Iyengar J. Tomasi, V. Barone, B. Mennucci, M. Cossi, G. Scalmani, N. Rega, G.A. Petersson, H. Nakatsuji, M. Hada, M. Ehara, K. Toyota, R. Fukuda, J. Hasegawa, M. Ishida, T. Nakajima, Y. Honda, O. Kitao, H. Nakai, M. Klene, X. Li, J.E. Knox, H.P. Hratchian, J.B. Cross, V. Bakken, C. Adamo, J. Jaramillo, R. Gomperts, R.E. Stratmann, O. Yazyev, A.J. Austin, R. Cammi, C. Pomelli, J.W. Ochterski, P.Y. Ayala, K. Morokuma, G.A. Voth, P. Salvador, J.J. Dannenberg, V.G. Zakrzewski, S. Dapprich, A.D. Daniels, M.C. Strain, O. Farkas, D.K. Malick, A.D. Rabuck, K. Raghavachari, J.B. Foresman, J.V. Ortiz, Q. Cui, A.G. Baboul, S. Clifford, J. Cioslowski, B.B. Stefanov, G. Liu, A. Liashenko, P. Piskorz, I. Komaromi, R.L. Martin, D.J. Fox, T. Keith, M.A. Al-Laham, C.Y. Peng, A. Nanayakkara, M. Challacombe, P.M.W. Gill, B. Johnson, W. Chen, M.W. Wong, C. Gonzalez, J.A. Pople, Gaussian 03, Gaussian, Inc. Wallingford, CT, 2003.

[39] A.D. Becke, Journal of Chemical Physics 98 (1993) 5648-5652.

[40] C. Lee, W. Yang, R.G. Parr, Physical Review B-Condensed Matter Material Physics 37 (1988) 785-789.

[41] Spartan'08 Wavefunction, Inc. Irvine, CA.

[42] L.P. Hammett, Physical Organic Chemistry, 2nd ed., McGraw-Hill, New York, 1970 , p. 367.

Use of arithmetical $\Sigma \sigma$ to measure electronic effects, when two or more substituents are present, is a standard procedure for evaluation of free energy relationships.

[43] O. Bortolini, V. Conte, Journal of Inorganic Biochemistry 99 (2005) 1549-1557

[44] M. Časný, D. Rehder, Dalton Transactions (2004) 839-846, and refs. cited therein.

[45] G. Zampella, P. Fantucci, V.L. Pecoraro, L. De Gioia, Journal of the American Chemical Society 127 (2005) 953-960.

[46] C.J. Schneider, G. Zampella, C. Greco, V.L. Pecoraro, L. De Gioia, European Journal of Inorganic Chemistry (2007) 515-523.

[47] In Ref. [43], trigonal bipyramid vanadium complexes are studied where the protonated oxygen is found at binding distances of $2.03-2.08 \AA$ from the vanadium centre. The different results obtained for salophen and salen systems, where that oxygen is located at larger distances, may be ascribed to the their octahedral structure, which hampers the binding of a further coordinating atom.

[48] F. Ding, J.M. Smith, H. Wang, Journal of Organic Chemistry 74 (2009) 2679-2691. 
[49] C.J. Schneider, J.E. Penner-Hahn, V.L. Pecoraro, Journal of the American Chemical Society 130 (2008) 2712-2713.

[50] R.R. Everett, J.R. Kanofsky, A. Butler, Journal of Biological Chemistry 265 (1990) 4908-4914.

[51] J.W.P.M. Van Schijndel, P. Barnett, J. Roelse, E.G.M. Vollenbroek, R. Wever, European Journal of Biochemistry 225 (1994) 151-157.

[52] P. Adão, J. Costa Pessoa, R.T. Henriques, M.L. Kuznetsov, F. Avecilla, M.R. Maurya, U. Kumar, I. Correia, Inorganic Chemistry 48 (2009) 3542-3561.
[53] I.V. Yudanov, P. Gisdakis, C. Di Valentin, N. Rösch, European Journal of Inorganic Chemistry (1999) 2135-2145.

[54] E. Kühn, A.M. Santos, R.W. Rocksy, E. Herdweck, W. Scherer, P. Gisdakis, I.V. Yudanov, C. Di Valentin, N. Rösch, Chemistry-A European Journal 5 (1999) 3603-3615.

[55] F.C. Di Valentin, P. Gisdakis, I.V. Yudanov, N. Rösch, Journal of Organic Chemistry 65 (2000) 2996-3004.

[56] S. Lovat, M. Mba, H.C. Abbenhuis, D. Vogt, C. Zonta, G. Licini, Inorganic Chemistry 48 (2009) 4724-4728. 